\title{
Study on the Water Invasion and Its Effect on the Production from Multilayer Unconsolidated Sandstone Gas Reservoirs
}

\author{
Yong Hu, ${ }^{1,2}$ Xizhe Li $\mathbb{D},{ }^{1,2}$ Weijun Shen $\mathbb{D},{ }^{3,4}$ Changmin Guo, ${ }^{1,2}$ Chunyan Jiao, ${ }^{1,2}$ Xuan Xu, ${ }^{1,2}$ \\ and Yuze $\mathrm{Jia}^{5}$ \\ ${ }^{1}$ Research Institute of Petroleum Exploration \& Development, PetroChina, Beijing 100083, China \\ ${ }^{2}$ Key Laboratory of Gas Reservoir Formation and Development, CNPC, LangFang 065007, China \\ ${ }^{3}$ Key Laboratory for Mechanics in Fluid Solid Coupling Systems, Institute of Mechanics, Chinese Academy of Sciences, \\ Beijing 100190, China \\ ${ }^{4}$ School of Engineering Science, University of Chinese Academy of Sciences, Beijing 100049, China \\ ${ }^{5}$ College of Earth and Planetary Sciences, University of Chinese Academy of Sciences, Beijing 100049, China
}

Correspondence should be addressed to Xizhe Li; 1xz69@petrochina.com.cn and Weijun Shen; wjshen763@imech.ac.cn

Received 10 April 2021; Revised 3 June 2021; Accepted 14 June 2021; Published 26 July 2021

Academic Editor: Steffen Berg

Copyright ( $) 2021$ Yong Hu et al. This is an open access article distributed under the Creative Commons Attribution License, which permits unrestricted use, distribution, and reproduction in any medium, provided the original work is properly cited.

\begin{abstract}
Water invasion is a common occurrence in multilayer unconsolidated gas reservoirs, which results in excessive water production and reduces the economic life of gas wells. However, due to multiple layers, active edge water, and strong heterogeneity, the mechanism of water invasion and its effect in the unconsolidated sandstone gas reservoir require understanding in order to improve efficiency and minimize economic cost. In this study, an experimental study on edge water invasion of the multilayer commingled production in unconsolidated sandstone gas reservoirs was conducted to understand the water invasion process along with different permeability layers. The results show that the edge water invasion in the commingling production is mainly affected by two major factors including reservoir permeability and gas production rate, which jointly control the encroaching water advance path and speed. The nonuniform invade of edge water may occur easily and water prefers to invade toward the gas well along with high permeability layers when the commingling production is in the condition of large permeability gradient and high production rate. The bypass flow will occur when there are high permeability channels between the layers, which causes water blocking to low-permeability layers and periphery reservoirs far away from gas wells. The findings of this study can help for a better understanding of water invasion and the effects of reservoir properties so as to optimize extraction conditions and predict gas productivity in unconsolidated sandstone gas reservoirs.
\end{abstract}

\section{Introduction}

As a clean and efficient low-carbon energy, natural gas has been attracting greatly wide concerns from governments around the world, which exhibits an increasingly broad development prospect [1]. The natural gas resources in China are rather abundant, and the gas reserves and production are increasing rapidly. According to the statistics from PetroChina Company Limited, China's natural gas geological resources have exceeded 220 trillion cubic meters in 2015, and the recoverable gas resources were about $31 \%$ of total resources, and the annual production increased from 17.4 billion cubic meters in 1995 to 135 billion cubic meters in 2015 with an average annual growth rate of $11 \%$ [2-4]. The Quaternary unconsolidated sandstone gas reservoir in the Qaidam Basin, Northwest China, is an important strategic successor gas source for the West-East Gas Pipeline project, which belongs to a rare biogenetic gas reservoir $[5,6]$. Geologically, the gas reservoir is characterized by long interval, multiple layers, and active edge water, which is based on the multilayer commingled production, and there exist lots of difficult problems to solve in the production and 
development [7]. Therefore, it is very important to develop the gas reservoir effectively and guarantee a stable gas supply in the sustainable development of the national economy.

Most of the gas reservoirs in China belong to water-drive gas reservoirs surrounded by aquifers, in which there are about 40 to 50 percent of gas reservoirs with active edgeand-bottom water $[8,9]$. Due to the existence of edge-andbottom water in gas reservoirs, the reservoir pressure will gradually decrease with the exploitation of gas reservoirs, which results in the invasion of the edge-and-bottom water into the gas pay zones. The gas-water two-phase flow occurs in gas reservoirs with the edge-and-bottom water drive, and the gas phase permeability will be decreased, which consequently interferes with gas production and impacts on the recovery factor of gas reservoirs [10-12]. In addition, water invasion can also block a large amount of gas through snapping, bypassing and water locking in gas reservoirs, which will greatly reduce the gas production of a single well [1315]. Thus, understanding the questions such as water invasion in gas reservoirs and its effects on gas production is significant for predicting gas productivity and improving recovery rate during the development of gas reservoirs.

The problem of water invasion in gas reservoirs has always been one of the major concerns in terms of productivity, increased operating costs, and environmental effects, and there have been many studies carried out on water invasion in gas reservoirs and its effects on gas productivity in the past years. Persoff and Pruess [16] and Zhou et al. [17] used a transparent microphysical model of a water-driven gas experiment to analyze the water invasion, and they considered that water would trap the gas in the matrix block by means of circumfluence, cut off phenomenon, and water locking. Tokunaga and Wan $[18,19]$ conducted water films flow on fracture surfaces under near-zeromatric potentials and examines the possibility of fast unsaturated flow along the macroscopic rock fracture surface. Saad et al. [20] and Bahrami et al. [21] analyzed the problem of water coning in naturally fractured reservoirs with the experiment and field data, respectively. Perez et al. [22] applied a coning radial model to analyze the occurrence of coning in naturally fractured reservoirs. Hu et al. [23] conducted the water invasion mechanism of gas reservoirs under horizontal fracture conditions and analyzed the changes of water saturation of reservoirs at different locations from the bottom of the well during gas reservoir depletion. Azim [24] developed a fully coupled poroelastic multiphase fluid flow model to evaluate the water invasion in naturally fractured reservoir under the effects of fluid properties. Shen et al. [25] and Fang et al. [26] used full-diameter core experiments to analyze the effects of different influencing factors on water invasion in pore gas reservoirs. Based on the material balance equation, Kabir et al. [27] and Patacchini [28] analyzed and predicted the water invasion intensity and speed combined with the production data. Although there were a lot of studies conducted on the water invasion of gas reservoirs, the above studies focused on naturally fractured gas reservoirs. And water invasion in the multilayer unconsolidated sandstone gas reservoir was somewhat lacking. The unconsolidated sandstone gas reservoir in the Qaidam Basin is characterized by multiple layers and strong heterogeneity, and there exist many uncertainties in the gas production. Hence, there is an extreme necessity to understand the mechanism of generating edge water nonuniform water invasion and evaluate the effects on different edge water so as to predict gas production and optimize the producing method in the unconsolidated sandstone gas reservoir.

In this study, the physical experiment of edge water invasion in the commingling production was established to understand the water invasion process along with the reservoirs with different permeability layers, based on the geological characteristics of unconsolidated sandstone gas reservoirs. Then, the edge water invasion characteristics and mechanism of the multilayer production were analyzed. Furthermore, the effects of edge water invasion on the development of gas reservoirs such as gas phase seepage capability, recovery rate, and residual gas storage were determined. The results can provide the theoretical guidance for establishing a reasonable gas recovery rate and water control development in unconsolidated sandstone gas reservoirs.

\section{Gas Reservoir Geological Characteristics and Experimental Method}

2.1. Gas Reservoir Geological Characteristics. The Quaternary unconsolidated sandstone gas reservoir of the Sebei gas field is located in the Qaidam Basin, Northwest China, which is mainly a structural gas reservoir [6]. The internal structures of the gas reservoir are intact without any faults developed and their lithological changes are small. The gas reservoir has many gas layers in structural high positions with large thickness while there are few gas layers in structural low positions with small thickness, which is surrounded by edge water. There exists a set of lacustrine facies beach-bar sandstone with sedimentary subfacies including shore swamp, shore lake, shallow lake and semideep lake subfacies, and sedimentary microfacies including sand bank, beach sand, sand sheet, mud bank, and marsh mud microfacies in the gas reservoir.

2.2. Experimental Method. Based on the geological multilayer characteristics of the unconsolidated sandstone gas reservoir in the Qaidam Basin, Northwest China, the characteristics of reservoir heterogeneity and edge water invasion are considered, and a set of physical simulation experimental methods on edge water invasion during the commingling production is established to understand the edge water invasion in the unconsolidated sandstone gas reservoirs. The experimental apparatus for physical simulation of water invasion in multilayer commingled production of gas reservoirs are shown in Figure 1, which is mainly composed of the confining pressure, water body, gas source, experimental model, gas rate control, and gas-water separation measurement system. The experiment features four basic characteristics as follows: (1) four sets of cores with different magnitudes of permeability are selected to assembly connect so as to reproduce the longitudinal multigas layer geological model, and the maximum permeability difference is 12.6 ; (2) high-precision back pressure and confining pressure control systems are used to 


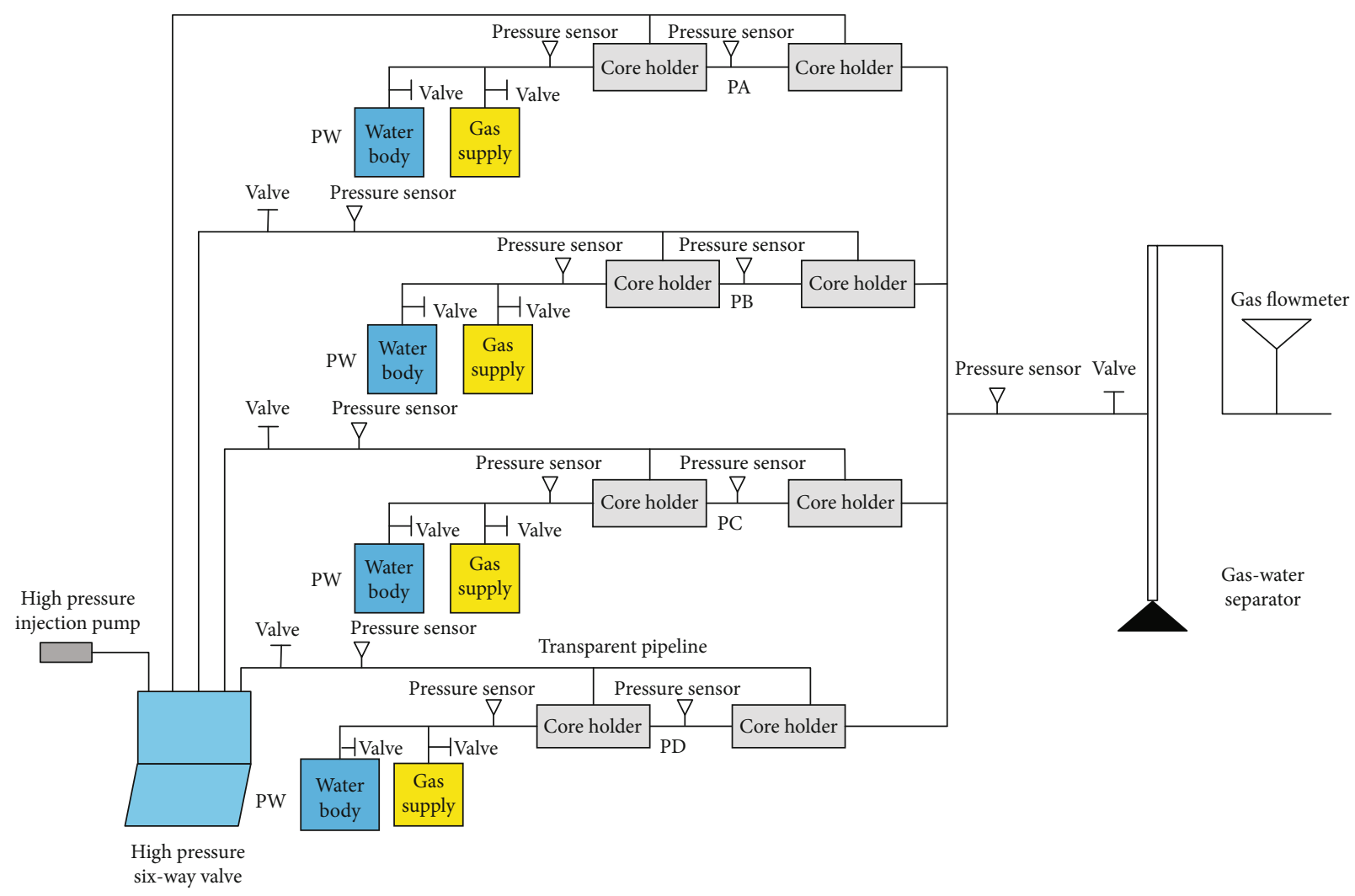

FIGURE 1: Experimental apparatus for physical simulation of water invasion in multilayer commingled production of gas reservoirs.

achieve the gas well exploitation, which can be simulated under any production rates or any production pressure difference; (3) the high-pressure transparent pipelines are connected in series between the two core holders of each group to visualize observation of the water invasion progress process as illustrated in Figure 2; (4) the encroaching water advance speed can be calculated in the experiment. When the edge water can be pushed to the transparent pipeline, it can be calculated according to the length of the core and the time for making it into the transparent pipeline. When it cannot be pushed into the transparent pipeline, the core is removed at the end of the experiment, and the advanced speed can be calculated based on the length of the core with water invasion and the time.

To understand the mechanism of edge water invasion and its effects during the multilayer commingled production in unconsolidated sandstone gas reservoir, the following experimental schemes are designed in this study: (1) four sets of cores with different permeability are used to simulate the commingled production with the vertical four gas layers, as shown in Table $1 ;$ (2) the encroaching water advance process in different permeability layers can be observed by the series connection experiment flow of high-pressure transparent pipeline; (3) different production rates $(20 \mathrm{~mL} / \mathrm{min}, 50$ $\mathrm{mL} / \mathrm{min}, 80 \mathrm{~mL} / \mathrm{min}, 100 \mathrm{~mL} / \mathrm{min}, 150 \mathrm{~mL} / \mathrm{min}$ ) are adopted in the experiment to simulate the gas well exploitation process and study the effects of production rate on the water invasion; (4) the core is saturated with gas until the pore pressure is at around $4 \mathrm{MPa}$, and the outside of the gas layer is connected to a water body with a constant pressure as shown in Figure 2; (5) in the experimental process, the parameters such as experimental time, reservoir pressure, water invasion path, and gas production rate are recorded to analyze the encroaching water advance speed and the effects of edge water invasion on the gas phase seepage capacity and recovery rate as well as the residual gas storage.

\section{Results and Discussion}

\subsection{Edge Water Invasion Characteristics of the Multilayer Production}

3.1.1. Characteristics of the Encroaching Water Advance Path. In this study, the characteristics of the encroaching water advance path in the gas reservoir multilayer production are recorded through the visualized experimental process, which is illustrated in Figure 1. According to the analysis results, the characteristics diagram of the encroaching water advance path is shown in Figure 2. From the result of Figure 2, it can be observed that the encroaching water advance path is mainly influenced by reservoir permeability and distribution and gas production rate. The commingling production in gas reservoirs with four layers of different permeability is conducted in the experiment; due to the permeability difference in the gas layers, the edge water exhibits the nonuniform advancement characteristics. The water invasion preferentially advances into the gas well along with two layers with the permeability of $24.4 \mathrm{mD}$ and $9.34 \mathrm{mD}$, while the water invasion in the layers with the permeability of $5.37 \mathrm{mD}$ and $1.93 \mathrm{mD}$ is weak. The results imply that the reservoir 


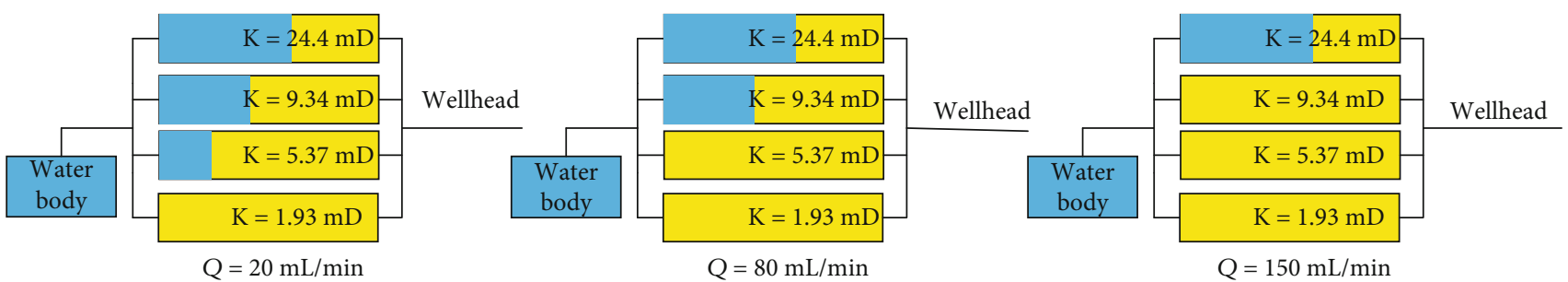

FIgURE 2: Characteristics diagram of the encroaching water advance path.

permeability and distribution are the dominant factors of the water invasion path. When the reservoir permeability exceeds $10 \mathrm{mD}$, it will be the key channel for water invasion. Besides, the gas production rate is also an important factor on the water invasion path. When the gas production rate is 20 $\mathrm{mL} / \mathrm{min}$, the edge water is uniformly pushed along three layers with the permeability of $24.4 \mathrm{mD}, 9.34 \mathrm{mD}$, and 5.37 $\mathrm{mD}$, respectively. Once the gas production rate reaches 150 $\mathrm{mL} / \mathrm{min}$, the edge water rushes along the single direction in the reservoir with the permeability of $24.4 \mathrm{mD}$, which implies that the gas production rate is a key factor affecting water invasion advance path. In addition, when the reservoir is characterized by strong heterogeneous, a larger gas production rate will result in nonuniform water invasion easily.

3.1.2. Characteristics of the Encroaching Water Advance Speed. According to the encroaching water advance path and experimental time, the calculation of the encroaching water advance speed can be expressed as follows:

$$
v=L / t
$$

where $v$ is the encroaching water advance speed, $\mathrm{cm} / \mathrm{min} ; L$ is the encroaching water advance path, $\mathrm{cm}$; and $t$ is the experimental time, min.

Based on the experimental results, the effects and comparisons of production rate on different encroaching water advance speeds are illustrated in Figure 3 and Table 2 (no water invasion is abbreviated as NWI). From the results of Figure 2 and Table 2, it can be seen that the encroaching water advance speed is also influenced by both reservoir permeability and production rate. When the production rate is low, the edge water is relatively uniformly pushed along the multiple layers, and the encroaching water advance speed is slower. For instance, when the production rate is $20 \mathrm{~mL} / \mathrm{min}$ in the experiment, the edge water is uniformly pushed along three gas layers with the permeability of $24.4 \mathrm{mD}, 9.34 \mathrm{mD}$, and $5.37 \mathrm{mD}$, and the advance speeds are $0.64 \mathrm{~cm} / \mathrm{min}, 0.60$ $\mathrm{cm} / \mathrm{min}$, and $0.34 \mathrm{~cm} / \mathrm{min}$, respectively; when the production rate is $50 \mathrm{~mL} / \mathrm{min}, 80 \mathrm{~mL} / \mathrm{min}$, or $100 \mathrm{~mL} / \mathrm{min}$, and the edge water permeability is $24.4 \mathrm{mD}$ and $9.34 \mathrm{mD}$, it is pushed nonuniformly in both gas layers and the advance speed is obviously increased between $0.92 \mathrm{~cm} / \mathrm{min}$ and $1.71 \mathrm{~cm} / \mathrm{min}$. When the production rate reaches $150 \mathrm{~mL} / \mathrm{min}$, it will rush unidirectional advance along with the gas layer with the permeability of $24.4 \mathrm{mD}$, and the encroaching water advance speed is $2.19 \mathrm{~cm} / \mathrm{min}$.

As previously mentioned, the rule of edge water invasion during the commingling production in gas reservoirs is mainly affected by the reservoir permeability and distribution and gas production rate. The two influencing factors jointly control the encroaching water advance path and speed. When the commingling production development is under the conditions with large permeability contrast and high production rate, the edge water is prone to nonuniform rush. The water invasion preferentially advances along with the high permeability layers into gas wells, and the encroaching water advance speed is fast. If the gas production rate is properly reduced, the edge water is pushed relatively uniformly along multiple layers, and the advance speed will be much slower than that in a single high permeability layer.

\subsection{Edge Water Invasion Mechanism of the Multilayer Production}

3.2.1. Nonuniform Rush of Edge Water along with High Permeability Layers. Permeability is an important property of the reservoir rock that measures the capacity of the formation to transmit fluid, and there exist a few preferred pathways that water flow through the high permeability reservoir [29-31]. In this study, the threshold pressure of gas-water seepage flows in an unconsolidated sandstone reservoir is illustrated in Figure 4. Threshold pressure is the minimum pressure at which the fluid begins to flow in the low permeability reservoir. From the result of Figure 4, as can be seen, there are obvious differences in the threshold pressure of gas-water seepage flow in different permeability reservoirs. For unconsolidated sandstone reservoir with the permeability greater than $10 \mathrm{mD}$, the threshold pressure of gas flooding is generally less than $1.0 \mathrm{MPa}$. When the permeability of the unconsolidated sandstone reservoirs is no more than $10 \mathrm{mD}$, the threshold pressure of gas-water seepage flow is generally greater than $1.0 \mathrm{MPa}$. The lower the reservoir permeability is, and the higher the threshold pressure of gas-water seepage flow is. Thus, when the commingling production is in multiple gas layers with different magnitudes of reservoir permeability, gas and water will be prone to choosing preferential a seepage path along with high permeability layers under the same displacement pressure. As the displacement pressure increases, i.e., the production pressure difference is increased, gas and water can be able to form seepage flows along with the relatively low permeability reservoirs. This is the primary reason why the edge water will choose to rush along high permeability layers during commingling production in gas reservoirs.

3.2.2. Effect of Gas Production Rate on Nonuniform Advancement of Water Invasion. The gas production rate is 
TABLE 1: Some properties of unconsolidated sandstone core samples used in this study.

\begin{tabular}{lcccccc}
\hline Group & Sample & Well & Permeability $(\mathrm{mD})$ & Porosity $(\%)$ & Length $(\mathrm{cm})$ & Diameter $(\mathrm{cm})$ \\
\hline \multirow{2}{*}{ Group I, series } & $1-2-7$ & Tai4-31 & 1.93 & 29.4 & 5.495 & 2.355 \\
& $1-2-8$ & Tai4-31 & 2.11 & 29.4 & 29.645 & 2.386 \\
Group II, series & $5-3-2$ & Tai4-31 & 9.34 & 27.0 & 3.398 & 5.625 \\
& $6-5-1$ & Tai4-31 & 10.2 & 53.6 & 3.693 \\
Group III, series & $1-3-5$ & Tai4-31 & 5.37 & 3.2 & 5.394 & 3.707 \\
& $1-4-1$ & Tai4-31 & 5.71 & 36.7 & 4.535 & 2.394 \\
Group IV, series & $1-5-3$ & Tai4-31 & 24.4 & 37.2 & 4.438 \\
\hline
\end{tabular}

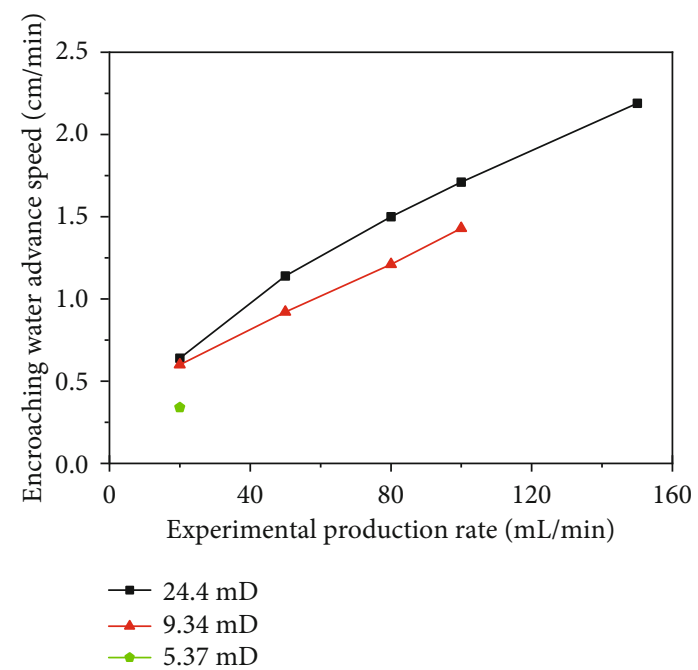

FIGURE 3: Effects of production rate on different encroaching water advance speeds.

TABLE 2: Comparison of the different encroaching water advance speeds.

\begin{tabular}{lccccc}
\hline \multirow{2}{*}{ Permeability $(\mathrm{mD})$} & \multicolumn{6}{c}{ Encroaching water advance speeds under } \\
& 20 & 50 & 80 & 100 & 150 \\
\hline 24.4 & 0.64 & 1.14 & 1.5 & 1.71 & 2.19 \\
9.34 & 0.60 & 0.92 & 1.21 & 1.43 & NWI \\
5.37 & 0.34 & NWI & NWI & NWI & NWI \\
1.93 & NWI & NWI & NWI & NWI & NWI \\
\hline
\end{tabular}

a significant parameter during the gas reservoir exploitation, which affects water invasion and ultimate recovery of gas reservoirs $[8,32]$. In order to understand the effect of gas production rate on nonuniform water invasion, the pressure difference between water bodies and different permeability reservoirs is measured by conducting water invasion physical simulation experiments on different production rates. Figure 5 shows the pressure difference between water bodies and different permeability reservoirs on different production rates. From the result of Figure 5, as can be seen, water invasion is influenced by gas production rates, when the pressure

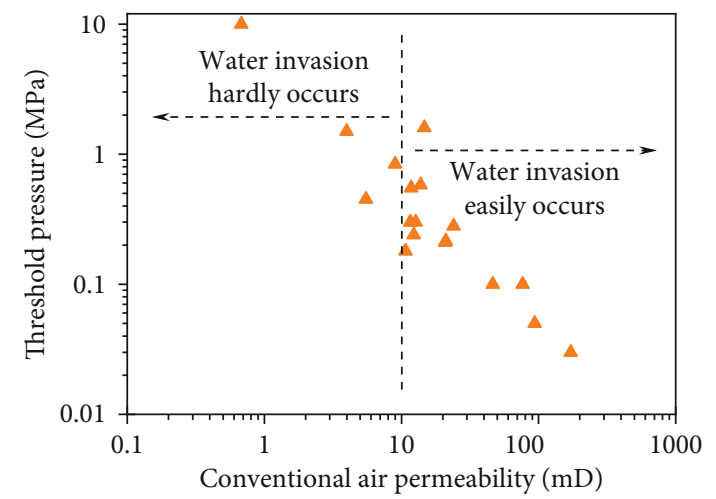

Figure 4: Threshold pressure of gas-water seepage flow in unconsolidated sandstone reservoirs.

difference between water bodies and different permeability reservoirs is large. The gas supply is mainly from the high permeability layers when the gas production rate is more than $100 \mathrm{~mL} / \mathrm{min}$, and the pressure difference between the water body and high permeability layers is much larger than that between the water body and low-permeability layers. Due to the pressure difference between the water body and the reservoir layers, when the pressure difference is 3.99 $\mathrm{MPa} \quad(\mathrm{PW}-\mathrm{PA}=4.11 \mathrm{MPa}, \mathrm{PW}-\mathrm{PD}=0.12 \mathrm{MPa})$, the water body is pushed forward along the high permeability layers. When the gas production rate is $20 \mathrm{~mL} / \mathrm{min}$, the pressure difference between the water body and the reservoir with each scale of permeability will be reduced. For example, when the pressure difference is $2.80 \mathrm{MPa}(\mathrm{PW}-\mathrm{PA}=3.0 \mathrm{MPa}$, $\mathrm{PW}-\mathrm{PD}=0.2 \mathrm{MPa})$ in the experiment, which implies that if the production rate is properly controlled, the pressure differences between the edge water and the reservoir with different scales of permeability reservoir are close, and the water invasion is more easily pushed uniformly along the permeability reservoirs. When the gas production rate is high, the gas supply capacity of the high permeability layer is much larger than that of the low permeability layer, and the high permeability layer will be produced faster than the low permeability layer, which results in the pressure difference between the water body and the high permeability layers greater than that between the water body and the low permeability layers. Consequently, the water body will 


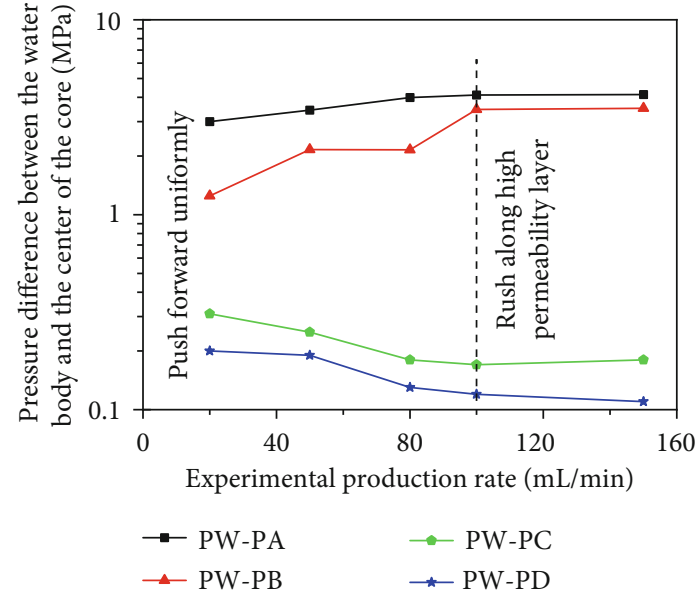

Figure 5: Pressure difference between water body and different permeability reservoirs on different production rates.

preferentially rush advance along with the high permeability layers under high production rate conditions.

\section{Effects of the Edge Water Invasion}

4.1. Effect on the Gas Phase Seepage Capability. The water production from gas-producing well is a common occurrence observed in gas reservoirs, which results in the watergas two-phase filtration and reduces gas phase seepage capability [33-35]. In this study, the gas permeability measurement under residual water saturation is conducted on the unconsolidated sandstone cores with different permeabilities. The relationship between conventional permeability and gas permeability under the residual water saturation is shown in Figure 6. From the result of Figure 6, it can be observed that there are significant differences in the effect of residual water saturation on the gas phase seepage capacity of different permeability sandstone reservoirs. Compared with the permeability of dry cores, there is a great effect on the gas phase seepage capacity of the reservoirs with the permeability less than $5 \mathrm{mD}$, and the gas phase permeability under residual water saturation decreases by nearly $100 \%$. For the cores with the permeability of $5 \sim 50 \mathrm{mD}$, the gas phase permeability under residual water saturation drops of more than $90 \%$, and the gas phase permeability under residual water saturation declines by more than $80 \%$ when the permeability exceeds $50 \mathrm{mD}$. Hence, the water will have a great influence on the gas flow seepage capacity of the reservoirs with the permeability less than $5 \mathrm{mD}$, and water invasion rushing along the high permeability layers should be avoided so as not to form water blocking during the development in the low permeability gas reservoir.

4.2. Effect on the Recovery Rate. Due to the existence of edgeand-bottom water in gas reservoirs, the edge and bottom water will invade the gas pay zones with the gas reservoir exploitation, which leads to the lower recovery rate of gas reservoirs, and some previous studies have indicated the recovery rate of water-driven gas reservoirs was significantly lower than that of dry gas reservoirs [36-38]. In the study, three

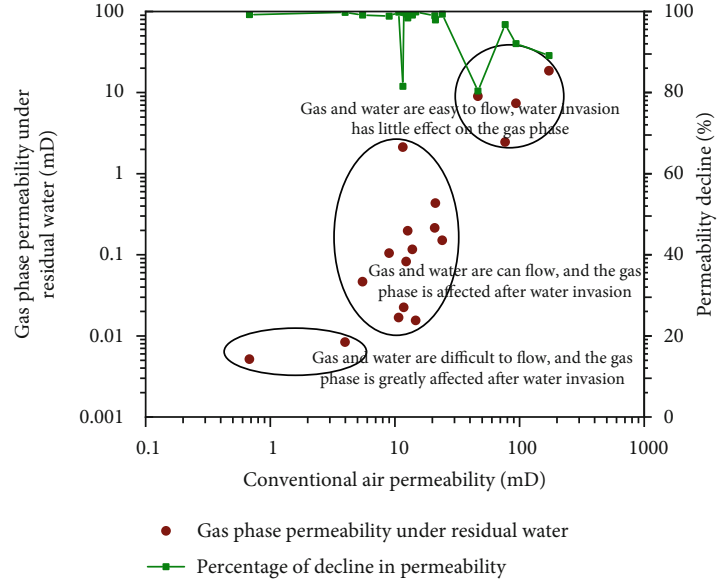

FIGURE 6: Relationship between conventional permeability and gas permeability under residual water saturation.

physical models, including no water invasion, water invasion without bypass flow, and water invasion with bypass flow, are designed to analyze the effect on the recovery rate during the production. Figure 7 illustrates the recovery rate comparison of gas reservoirs with and without water invasion. From the result of Figure 7, it can be seen that the recovery rates of the two water invasion models are significantly lower compared with the recovery rate of the no water invasion model, which indicates that it will have a major influence on gas reservoir recovery rate when the water invasion occurs in the gas reservoir development. The water invasion with bypass flow has the lowest recovery rate, which is about $30 \%$ lower than that of the no water invasion. While the recovery rate of water invasion without bypass flow ranges between $80 \%$ and $90 \%$, which is about $10 \%$ lower than that of the no water invasion model. Although this is an experimental result, it can still reflect the changing trend, which is used as a reference during the gas reservoir development evaluation. However, the results seem to be optimistic in terms of the recovery rate itself, and it is difficult to reflect the overall gas recovery, and the simulation results can be regarded as the recovery rate of the near well areas.

4.3. Effect on the Residual Gas Storage. The gas recovery under water drive in gas reservoirs appears to depend on an important way on the residual gas saturation, and some studies have indicated that gas recovery may be as low as 45 percent of the initial gas in place due to the water invasion [39, 40]. In order to understand the effect on the residual gas storage, the residual gas ratio of each group of cores is analyzed at the end of the physical simulation experiment in this study, and the residual gas ratio is defined as the ratio between residual gas and the reserves. The experimental results of the residual gas ratio in different permeability cores are shown in Table 3. From the result of Table 3, as can be seen, there is a certain amount of residual gas that can hardly be recovered during the multilayers commingled production in gas reservoir. The ratio of residual gas to the reserves is in the range between $31 \%$ and $36 \%$, and the residual gas is mainly distributed in the low-permeability layers. For 


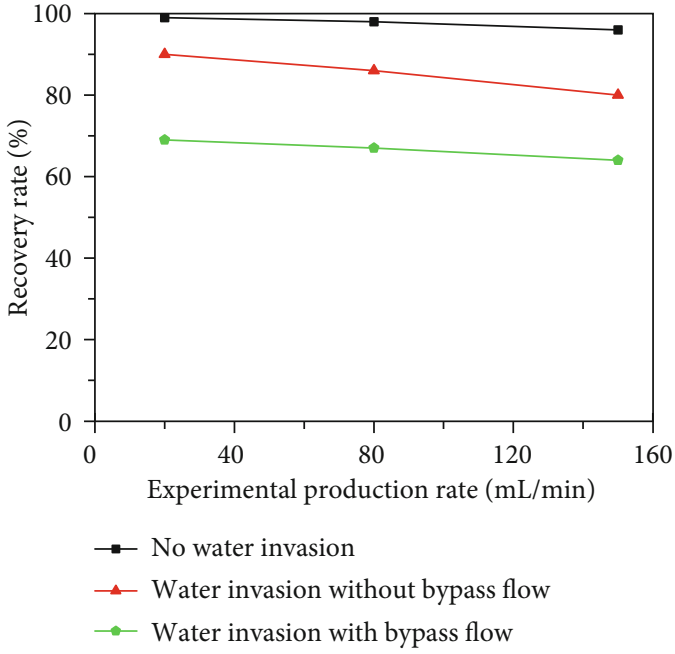

Figure 7: Recovery rate comparison of gas reservoirs with and without water invasion.

TABLE 3: Results of the residual gas ratio in core samples of different permeabilities.

\begin{tabular}{lccc}
\hline $\begin{array}{l}\text { Permeability } \\
\mathrm{mD}\end{array}$ & \multicolumn{3}{c}{ Residual gas ratio (\%) } \\
\hline 156.0 & $29 \mathrm{~mL} / \mathrm{min}$ & $80 \mathrm{~mL} / \mathrm{min}$ & $150 \mathrm{~mL} / \mathrm{min}$ \\
57.5 & 29 & 30 & 29 \\
11.7 & 32 & 30 & 32 \\
3.6 & 35 & 34 & 34 \\
Average value & 31 & 37 & 50 \\
\hline
\end{tabular}

instance, the ratio of residual gas in the gas layer with the permeability of $3.6 \mathrm{mD}$ is apparently higher than that in other gas layers. The gas production rate has a certain effect on the residual gas, especially in the low-permeability layers. The larger the gas production is, and the more the residual gas is. The overall ratio of residual gas in the gas layers is $31 \%$ when the gas production rate is $20 \mathrm{~mL} / \mathrm{min}$, while the overall residual gas ratio is $36 \%$ when the production rate is $150 \mathrm{~mL} / \mathrm{min}$.

\section{Summary and Conclusions}

In this study, based on the geological characteristics of an unconsolidated sandstone gas reservoir, the physical experiment of edge water invasion was conducted to understand the mechanism of water invasion and its effect on the development phase during the commingling production. Then, the edge water invasion characteristics and mechanism of the multilayer production were discussed, and the effects such as gas phase seepage capability, recovery rate, and residual gas storage on the edge water invasion were analyzed. According to the above results, the conclusions from this study are summarized as follows: (1) During the commingled production phase, the edge water invasion is mainly affected by reservoir permeability and gas production rate, and the two influencing factors jointly control the encroaching water advance path and speed. When the gas reservoir is characterized by strong heterogeneity, a larger gas production rate will cause easily nonuniform water invasion. (2) When the commingling production is in large permeability gradation and high production rate, the nonuniform rush of edge water along the high permeability layers will occur. While there exists interflow in the high-permeability channel, the bypass flow will emerge, and water block will be formed in the lowpermeability layers and the peripheral reservoirs, which results in a significant decline in productive capacity and recovery rate. (3) The residual water saturation is a great influence on the gas phase seepage capacity of the reservoir less than $5 \mathrm{mD}$. Compared with no water invasion, the recovery rates of water invasion with and without bypass flow decrease by $30 \%$ and $10 \%$, respectively, and there exists a certain amount of residual gas that can hardly be recovered during the commingling production, which is mainly distributed in the low-permeability layer.

\section{Data Availability}

The data used to support the findings of this study are included within the article.

\section{Conflicts of Interest}

The authors declare that they have no conflicts of interest.

\section{Acknowledgments}

This work was supported by the National Natural Science Foundation of China (NO. U1762216 and NO. 11802312) and by the Open Fund (PLN201810) of State Key Laboratory of Oil and Gas Reservoir Geology and Exploitation (Southwest Petroleum University). We also thank the support from the Youth Foundation of Key Laboratory for Mechanics in Fluid Solid Coupling Systems, Chinese Academy of Sciences.

\section{References}

[1] J. Y. Liu, S. X. Wang, N. Wei, X. Chen, H. Y. Xie, and J. Wang, "Natural gas consumption forecasting: a discussion on forecasting history and future challenges," Journal of Natural Gas Science and Engineering, vol. 90, article 103930, 2021.

[2] Y. F. Ma and Y. L. Li, "Analysis of the supply-demand status of China's natural gas to 2020," Petroleum Science, vol. 7, no. 1, pp. 132-135, 2010.

[3] W. J. Shen, X. Z. Li, T. R. Ma, J. C. Cai, X. B. Lu, and S. W. Zhou, "High-pressure methane adsorption behavior on deep shales: experiments and modeling," Physics of Fluids, vol. 33, no. 6, article 063103, 2021.

[4] X. Li, Z. Guo, Y. Hu et al., "Efficient development strategies for large ultra-deep structural gas fields in China," Petroleum Exploration and Development, vol. 45, no. 1, pp. 118-126, 2018.

[5] Y. Q. Dang, W. Z. Zhao, A. G. Su et al., "Biogenic gas systems in eastern Qaidam Basin," Marine and Petroleum Geology, vol. 25 , no. 4-5, pp. 344-356, 2008. 
[6] S. C. Zhang, Y. H. Shuai, L. Huang et al., "Timing of biogenic gas formation in the eastern Qaidam Basin, NW China," Chemical Geology, vol. 352, no. 1, pp. 70-80, 2013.

[7] S. Huang, Y. Wu, X. Meng, L. Liu, and W. Ji, "Recent advances on microscopic pore characteristics of low permeability sandstone reservoirs," Advances in Geo-Energy Research, vol. 2, no. 2, pp. 122-134, 2018.

[8] F. F. Fang, W. J. Shen, S. S. Gao, H. X. Liu, Q. F. Wang, and Y. Li, "Experimental study on the physical simulation of water invasion in carbonate gas reservoirs," Applied Sciences, vol. 7, no. 7, p. 697, 2017.

[9] C. Li, X. Li, S. Gao et al., "Experiment on gas-water two-phase seepage and inflow performance curves of gas wells in carbonate reservoirs: a case study of Longwangmiao Formation and Dengying Formation in Gaoshiti-Moxi block, Sichuan Basin, SW China," Petroleum Exploration and Development, vol. 44, no. 6, pp. 983-992, 2017.

[10] W. J. Shen, X. H. Liu, X. Z. Li, and J. L. Lu, "Water coning mechanism in Tarim fractured sandstone gas reservoirs," Journal of Central South University (English Edition), vol. 22, no. 1, pp. 344-349, 2015.

[11] W. J. Shen, F. Q. Song, X. Hu, G. M. Zhu, and W. Y. Zhu, "Experimental study on flow characteristics of gas transport in micro- and nanoscale pores," Scientific Reports, vol. 9, no. 1, article 10196, 2019.

[12] A. Movahhed, M. N. Bidhendi, M. Masihi, and A. Emamzadeh, "Introducing a method for calculating water saturation in a carbonate gas reservoir," Journal of Natural Gas Science and Engineering, vol. 70, no. 102942, article 102942, 2019.

[13] V. Suicmez, M. Piri, and M. Blunt, "Effects of wettability and pore-level displacement on hydrocarbon trapping," Advances in Water Resources, vol. 31, no. 3, pp. 503-512, 2008.

[14] S. Zendehboudi, A. Elkamel, I. Chatzis, M. A. Ahmadi, A. Bahadori, and A. Lohi, "Estimation of breakthrough time for water coning in fractured systems: experimental study and connectionist modeling," AICHE Journal, vol. 60, no. 5, pp. 1905-1919, 2014.

[15] K. Singh, H. Menke, M. Andrew et al., "Dynamics of snap-off and pore-filling events during two-phase fluid flow in permeable media," Scientific Reports, vol. 7, no. 1, pp. 1-13, 2017.

[16] P. Persoff and K. Pruess, "Two-phase flow visualization and relative permeability measurement in natural rough-walled rock fractures," Water Resources Research, vol. 31, no. 5, pp. 1175-1186, 1995.

[17] K. M. Zhou, N. Li, Q. X. Zhang, and X. G. Tang, "Experimental research on gas-water two phase flow and confined gas formation mechanism," Natural Gas Industry, vol. 22, no. S1, pp. 122-125, 2002.

[18] T. K. Tokunaga and J. M. Wan, "Water film flow along fracture surfaces of porous rock," Water Resources Research, vol. 33, no. 6, pp. 1287-1295, 1998.

[19] T. K. Tokunaga, J. M. Wan, and S. R. Sutton, "Transient film flow on rough fracture surfaces," Water Resources Research, vol. 36, no. 7, pp. 1737-1746, 2000.

[20] E. Saad, T. Darwich, and Y. Asaad, Water coning in fractured basement reservoirs, Society of Petroleum Engineers, 1995.

[21] H. Bahrami, S. Shadizadeh, and I. Goodarzniya, "Numerical simulation of coning phenomena in naturally fractured reservoirs," in 9th Iranian Chemical of Engineering Congress, Iran, November, 2004.
[22] E. Perez, F. Garza, and F. Samaniego-Verduzco, Water coning in naturally fractured carbonate heavy oil reservoir-a simulation study, Society of Petroleum Engineers, 2012.

[23] Y. Hu, X. Z. Li, X. G. Lu et al., "Varying law of water saturation in the depletion-drive development of sandstone gas reservoirs," Petroleum Exploration and Development, vol. 41, no. 6, pp. 790-793, 2014.

[24] R. Abdel Azim, "Evaluation of water coning phenomenon in naturally fractured oil reservoirs," Journal of Petroleum Exploration and Production Technology, vol. 6, no. 2, pp. 279-291, 2016.

[25] W. J. Shen, X. Z. Li, X. H. Liu, J. L. Lu, and C. Y. Jiao, "Physical simulation of water influx mechanism in fractured gas reservoirs," Journal of Central South University (Science and Technology), vol. 45, no. 9, pp. 3283-3287, 2014.

[26] F. F. Fang, W. J. Shen, X. Z. Li, S. S. Gao, H. X. Liu, and J. Li, "Experimental study on water invasion mechanism of fractured carbonate gas reservoirs in Longwangmiao Formation, Moxi block, Sichuan Basin," Environmental Earth Sciences, vol. 78, no. 10, pp. 1-11, 2019.

[27] C. Kabir, B. Parekh, and M. Mustafa, "Material-balance analysis of gas and gas-condensate reservoirs with diverse drive mechanisms," Journal of Natural Gas Science and Engineering, vol. 32, no. 1, pp. 158-173, 2016.

[28] L. Patacchini, "Peripheral water injection efficiency for material balance applications," Journal of Petroleum Science \& Engineering, vol. 149, no. 1, pp. 720-739, 2017.

[29] C. F. Tsang and I. Neretnieks, "Flow channeling in heterogeneous fractured rocks," Reviews of Geophysics, vol. 36, no. 2, pp. 275-298, 1998.

[30] C. L. Cheng, E. Perfect, B. Donnelly et al., "Rapid imbibition of water in fractures within unsaturated sedimentary rock," Advances in Water Resources, vol. 77, no. 1, pp. 82-89, 2015.

[31] X. H. Tan, J. Y. Liu, X. P. Li, L. H. Zhang, and J. C. Cai, “A simulation method for permeability of porous media based on multiple fractal model," International Journal of Engineering Science, vol. 95, no. 1, pp. 76-84, 2015.

[32] L. A. Høyland, P. Papatzacos, and S. M. Skjaeveland, "Critical rate for water coning: correlation and analytical solution," SPE Reservoir Engineering, vol. 4, no. 4, pp. 495-502, 1989.

[33] M. Li, W. J. Yang, Q. Y. Xiao, S. C. Liu, J. Zhang, and G. M. Peng, Determination of the Aquifer Activity Level and the Recovery of Water Drive Gas Reservoirs, Society of Petroleum Engineers, 2010.

[34] M. Rezaee, B. Rostami, M. Zadeh, and M. Mojarrad, Experimental Determination of Optimized Production Rate and Its Upscaling Analysis in Strong Water Drive Gas Reservoirs, Society of Petroleum Engineers, 2013.

[35] M. R. Mohammadi, H. Bahmaninia, S. Ansari et al., "Evaluation of asphaltene adsorption on minerals of dolomite and sandstone formations in two and three-phase systems," Advances in Geo-Energy Research, vol. 5, no. 1, pp. 39-52, 2021.

[36] R. G. Agarwal, R. al-Hussainy, and H. J. Ramey, "The importance of water influx in gas reservoirs," Journal of Petroleum Technology, vol. 17, no. 11, pp. 1336-1342, 1965.

[37] Y. Cheng, L. Mu, E. Zhu et al., "Water producing mechanisms of carbonate reservoirs gas wells: a case study of the Right Bank Field of Amu Darya, Turkmenistan," Petroleum Exploration and Development, vol. 44, no. 1, pp. 89-96, 2017. 
[38] X. Z. Li, Z. H. Guo, Y. J. Wan et al., "Geological characteristics and development strategies for Cambrian Longwangmiao Formation gas reservoir in Anyue gas field, Sichuan Basin, SW China," Petroleum Exploration and Development, vol. 44, no. 3, pp. 428-436, 2017.

[39] M. Li, T. Li, J. Q. Jiang, H. Yang, and S. C. Liu, "The gas recovery of water-drive gas reservoirs," Journal of Hydrodynamics, vol. 27, no. 4, pp. 530-541, 2015.

[40] C. Y. Xu, P. C. Li, and D. T. Lu, "Production performance of horizontal wells with dendritic-like hydraulic fractures in tight gas reservoirs," Journal of Petroleum Science \& Engineering, vol. 148, no. 1, pp. 64-72, 2017. 